in long-term mortality [deaths: $2 / 55$ (3\%) vs 3/14 (21\%); $\mathrm{p}=0.022]$ at a mean follow-up of 4.2 years from $\mathrm{MI}$.

Conclusion MR observed following AMI resolved completely in approximately one-quarter of patients at 6-month and 2year follow-up. Progression of mild MR at long-term follow-up appears to be associated with increased mortality and is predicted by lower LVEF and greater LVESVi predischarge.

Conflict of Interest None

\section{LONG TERM FOLLOW-UP AND OUTCOMES AFTER VALVE REPLACEMENT - A 10-YEAR, SINGLE-CENTRE EXPERIENCE OF THE HEART VALVE SURVEILLANCE CLINIC}

${ }^{1}$ Polyvios Demetriades, ${ }^{2}$ Rosie Oatham, ${ }^{1}$ Cheryl Oxley, ${ }^{1} T i m$ Griffiths, ${ }^{1}$ Sally Clews, ${ }^{1}$ Nigel Stokes, ${ }^{1}$ Grant Heatlie, ${ }^{1}$ Simon Duckett. 'University Hospitals of North Midlands NHS Trust, Stoke-on-Trent, UK; ${ }^{2}$ School of Medicine, Keele University, Stoke-on-Trent, UK

\subsection{6/heartjnl-2021-BCS.21}

Introduction The long-term management of patients following valve replacement is challenging. The fields of percutaneous and surgical valves are expanding rapidly, leading to increased service demands. Most patients in our institution are managed within a dedicated cardiac physiologist' run valve clinic. Initially, follow-up centred around ESC 2012 guidelines on the management of valve disease, which recommended a baseline clinical and echocardiographic assessment after surgery and lifelong annual clinical follow-up. In addition, they recommended annual echocardiogram 5 years for bioprosthetic valves with no specific guidance for mechanical valves. Locally, all patients enrolled into the valve clinic received annual clinical and echocardiographic assessment. In 2019, the BHVS/ BSE published more comprehensive guidance on long-term follow-up of these patients. The Covid-19 pandemic placed pressure on the NHS to reduce outpatient appointments. Prior to service alteration, we conducted an audit to expand our understanding of outcomes in these patients.

Methods We retrospectively analysed the data of all patients enrolled in our valve service. We assessed demographics, date and indication for surgery, prosthesis type and position, baseline assessment, frequency of follow-up and significant valverelated complications. Complications constituted: any degree of paravalvular regurgitation, $\geq$ moderate transvalvular regurgitation, raised transvalvular gradients, valve thrombosis, infective endocarditis, new LV dysfunction, need for reintervention, cardiac-related hospital admission and valverelated death.

Results We identified 294 patients who underwent valve replacement since clinic establishment in 2010. Patient demographics are shown in table 1 . Only $37 \%$ of patients had baseline echocardiogram following surgery. Once enrolled into the clinic, $82.7 \%$ had yearly clinical and echocardiographic assessment. Table 2 demonstrates the echocardiographic and clinical complications we identified. During follow up $20.7 \%$ developed regurgitation, 9.5\% developed abnormal gradients and one required re-intervention for re-stenosis. One patient had valve thrombosis and was managed medically. Additionally, 9.2\% were diagnosed with new LV dysfunction; four of these required admission with decompensated heart failure and one died. 3.4\% developed infective endocarditis; three required redo surgery and four died. Figure 1 provides a schematic of valve-related complications and outcomes. Importantly, all patients who required admission, re-do surgery or that died, presented acutely with symptoms; the complications were not picked-up by the valve clinic.

Conclusions Contrast to our expectations, we identified only a small number of valve-related complications. With pressures rising to reduce outpatient footprint, we are now in the process of safely adjusting our practice in line with the BHVS/ BSE recommendations, supported by the evidence generated by our audit. We strongly encourage departments review their current services and implement evidence-based guidelines in

Significant valve-related complications

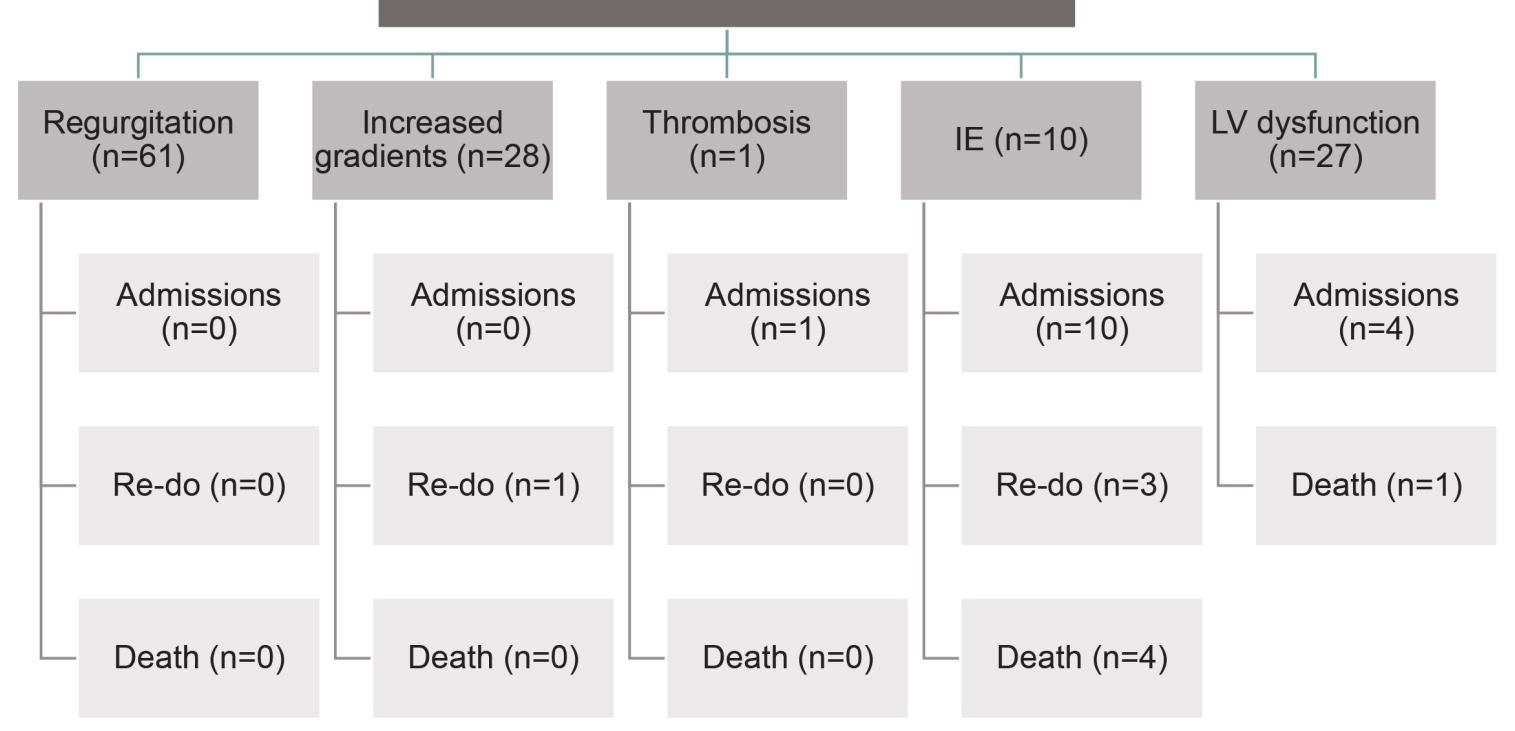

Abstract 21 Figure 1 Significant valve related complications and outcomes

${ }^{*}$ Regurgitation = any degree of paravalvular / $\geq$ moderate transvalvular; Increased gradients = above normal for specific valve type; IE=infective endocarditis 
Abstract 21 Table 1 Demographics of 294 patients with valve replacements enrolled in our service

\begin{tabular}{|c|c|c|c|c|c|c|}
\hline \multicolumn{7}{|c|}{ Median age at operation (years) } \\
\hline \multicolumn{7}{|l|}{71} \\
\hline \multicolumn{7}{|l|}{ Gender } \\
\hline Male & \multicolumn{2}{|c|}{ Female } & & & & \\
\hline $69.0 \%(\mathrm{n}=203)$ & \multicolumn{2}{|c|}{$31.0 \%(\mathrm{n}=91)$} & & & & \\
\hline \multicolumn{7}{|l|}{ Valve type } \\
\hline Bioprosthetic & Mechanical & Transcutaneous & Repair & & & \\
\hline $60.8 \%(n=179)$ & $27.2 \%(\mathrm{n}=80)$ & $4.5 \%(n=13)$ & $7.5 \%(n=22)$ & & & \\
\hline \multicolumn{7}{|l|}{ Position* } \\
\hline$A V R$ & $M V R$ & $A V R / M V R$ & $T V R$ & & & MV Repair \\
\hline \multirow[t]{2}{*}{$82.6 \%(\mathrm{n}=243)$} & \multirow[t]{2}{*}{$5.8 \%(\mathrm{n}=17)$} & \multirow[t]{2}{*}{$1.4 \%(n=4)$} & $A V R / T V R$ & $M V R / T V R$ & $\begin{array}{l}M V \\
\text { Repair/TVR }\end{array}$ & \multirow[t]{2}{*}{$\begin{array}{l}6.4 \% \\
(n=19)\end{array}$} \\
\hline & & & $0.7 \%(n=2)$ & $1.4 \%(n=4)$ & $1.7 \%(\mathrm{n}=5)$ & \\
\hline \multicolumn{7}{|l|}{ Indication** } \\
\hline$A S$ & $M R$ & IE & Other & & & \\
\hline $67.7 \%(\mathrm{n}=199)$ & $11.2 \%(\mathrm{n}=33)$ & $6.5 \%(n=19)$ & $14.6 \%(\mathrm{n}=43)$ & & & \\
\hline
\end{tabular}

${ }^{*} \mathrm{AVR}=$ Aortic Valve Replacement, MVR = Mitral Valve Replacement, TVR = Tricuspid Valve Repair, ${ }^{*} \mathrm{AS}=$ Aortic Stenosis, MR= Mitral Regurgitation, IE= Infective Endocarditis.

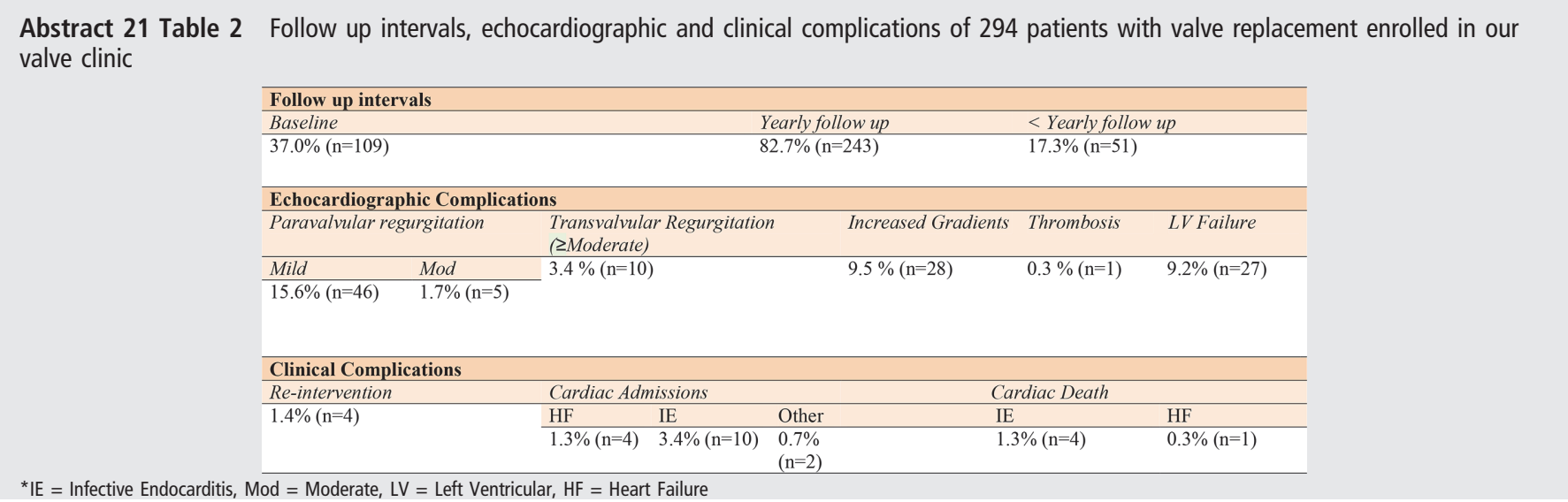

the long-term management of patients with valve replacements.

Conflict of Interest None

\section{PRE-PREGNANCY COUNSELLING IN CARDIOVASCULAR DISEASE: A SERVICE EVALUATION AT THE LEEDS TEACHING HOSPITALS NHS TRUST (LTHT) 2014-2020}

Kate Hamilton, Eleanor Joy, James Oliver, Kate Gatenby, Sarah Winfield, Thomas Everett, Stewart Prestwich, Tiffany Halsey, Kate English, Alexander Simms. The Leeds Teaching Hospitals NHS Trust, Leeds, UK

\subsection{6/heartjnl-2021-BCS.22}

Background The European Society of Cardiology (ESC) 2018 guidelines for the management of cardiovascular disease during pregnancy ${ }^{1}$ recommend women with cardiac disease receive pre-pregnancy counselling to facilitate informed decision making. Diagnoses are classified according to the mWHO score1, enabling a quantified risk of maternal morbidity and mortality. This estimated risk can be further adjusted based on individual anatomical, physiological and functional factors, allowing for tailored advice.

Aim To evaluate compliance with ESC guidelines1 on prepregnancy counselling at LTHT, including providing a quantified risk.
Methods Retrospective analysis of electronic records of 476 patients seen in the cardio-obstetrics clinic in LTHT 20142020. 241 met the inclusion criteria: 1. Known to LTHT cardiology services prior to first pregnancy 2. Cardiac diagnosis classifiable by $\mathrm{mWHO}$ class

Results Demographics of our patient cohort are in table 1. $77.2 \%$ had congenital heart disease (CHD), and $22.8 \%$ acquired disease. $66.8 \%$ received pre-pregnancy counselling, $32.3 \%$ of these were given a quantified risk (table 2). Rates of pre-pregnancy counselling were similar in CHD and acquired disease $(67.6 \%$ vs $65.0 \%) .8$ patients attended for

Abstract 22 Table 1 Demographics of patients

\begin{tabular}{llll}
\hline $\begin{array}{l}\text { mWHO } \\
\text { Classification }\end{array}$ & $\begin{array}{l}\text { Number of } \\
\text { patients }\end{array}$ & $\begin{array}{l}\text { Percentage } \\
\text { pregnancy }\end{array}$ & $\begin{array}{l}\text { Age at first } \\
\text { patients }\end{array}$ \\
\hline I & $<20$ & \\
II & $20-24$ & \\
II-III & $25-29$ & \\
III & $30-34$ & \\
IV & $35-39$ \\
& $40-45$ \\
& No pregnancy \\
& to date \\
\hline
\end{tabular}

